\title{
Examining English Language Learning Apps from A Second Language Acquisition Perspective
}

\author{
Sayed Ahmad Almousawi ${ }^{1}$ \\ ${ }^{1}$ English Language Instructor, Kuwait University, Kuwait \\ Correspondence: Sayed Ahmad Almousawi, English Language Instructor, Kuwait University, Kuwait. \\ Received: April 9, 2021 \\ Accepted: May 17, 2021 \\ Online Published: May 18, 2021 \\ doi:10.5430/ijhe.v10n5p166 \\ URL: https://doi.org/10.5430/ijhe.v10n5p166
}

\begin{abstract}
This study set out to explore dedicated language learning apps pedagogically while focusing mainly on aspects of second language acquisition. A total of 20 English language learning apps were collected for analysis. The study took one model of analysing course book materials and another, computer-assisted language learning model and combined them into one analytical framework with bespoke criteria, ensuring the analysis was most suitable for our case. The analytical framework which was developed reached a number of conclusions about dedicated language learning apps (DLLAs). The findings revealed that DLLAs tend to provide mechanical forms-focused practice without facilitating collaborative learning nor focusing on developing users' communicative competence, which suggests that DLLAs reflect a behaviouristic view of language learning. The conclusion offers some suggestions to improve DLLAs and proposes that, for the time being, educators should look beyond DLLAs and instead investigate how can apps that are not designed for language learning (generic apps) be used in the manner of DLLAs to avoid the issues that this paper identifies with them.
\end{abstract}

Keywords: mobile-assisted language learning, computer-assisted language learning, Language Learning Apps

\section{Introduction}

Since the advent of the internet in the late 1990's, technology has changed the way in which humans communicate and interact with one another. There have been many attempts to innovate in language learning through technology, beginning with computer-assisted language learning (CALL). By developing language learning courseware after the emergence of smartphones, computers have become mobile, leading to a new acronym: mobile-assisted language learning (MALL) which in turn generated language learning apps. However, little research has been conducted on the latter to find what these language learning apps offer from a second language acquisition perspective. Although there are several studies that examined language learning apps and MALL in general. Bruston (2014) \& Kerr (2014) research papers included the technical aspect of the apps in addition to pedagogy in their review which seemed, according to the papers, not the main problem with language learning apps. Rather it is the pedagogy which is lacking and needs more research on. Kim \& Kowen (2012) \& Rosell-Aguilar (2018) suggest that language learning apps are well pedagogically designed and popular among leaners and can be beneficial to the users. Thus, this paper sets out to investigate these claims.

\section{Research Background}

\subsection{Historical Development in Computer-Assisted Language Learning}

Learning through computers and other technologies is progressive. Jarvis and Achilleos (2013) state that CALL emerged in language education at the beginning of the 1980s. Davies et. al (2014) state that CALL development has been shaped by trends in language pedagogy and second language acquisition. Hockly (2016) states that the early development of CALL occurred in three stages, including behavioral/structural CALL, open CALL, and integrative CALL.

\subsubsection{Structural CALL}

Computer-based language learning processes in the initial stages of CALL development entailed fundamental engagement interactions and decontextualized practices between the learner and the computer. Arguably, the activities were referred to as tutorial CALL, which reflected a behaviorist viewpoint of language as a structural system of grammar, vocabulary, and pronunciation as at that time the behaviorism theory was almost dominant. 


\subsubsection{Open CALL}

Open CALL permits more complex and sophisticated engagement between the learner and computers. The open CALL approach attempted to follow the recent development in language learning where language was being taught for communicative purposes, emphasizing that grammar, for example, should also be taught implicitly rather than only explicitly (Warschauer \& Healy, 1998). At the open CALL stage, technology could now undertake a partial role as tutor, guiding students to discover language precepts. It also stresses that technology should be used as an enabling tool which allows learners to engage with language while also giving them an opportunity to produce some output (Hockly, 2016).

\subsubsection{Integrative CALL}

This stage was marked by the utilization of multimedia computer capabilities and the Internet (Davies et. al, 2014). This approach utilises computers and technology for communicative purposes, which emphasizes the socio-constructivist view of language learning that places language use in an authentic context (Warschauer \& Healy, 1998). This stage is aligned with learning though social interaction online and exposure to authentic materials (Hockly, 2016). This approach suggests that, unlike the open and restricted forms of CALL which use technology only in the classroom, technology should be omnipresent in learners' language acquisition, available to them at any time in their daily lives.

With computers forming the basis for learning, it is not surprising to witness alternative acronyms as the off-shoots of CALL. Because of this, developments in smartphones and eBooks, including Amazon's Kindle, have led to the creation of the acronym known as MALL. MALL stands for Mobile-Assisted Language Learning, which denotes the use of portable and personal devices to facilitate continuous language learning which holds the exact same attributes of CALL, only adding the 'mobile' aspect (Achilleos \& Jarvis, 2013) With the progressive utilization of highly mobile and portable technologies in learning, a third acronym has emerged from CALL and MALL. The new acronym is MALU, which adds the element 'use' instead of 'learning'. It is different from MALL in the sense that students use the mobile technology to produce output (whereas in MALL learners are only learning from the technology). Achilleos and Jarvis (2013) define MALU as non- native speakers using mobile devices to access and/or communicate information on a regular basis for a range of social or/and academic purposes in an L2. This is to say that MALU is more concerned with context than the language itself, which involves meaningful interactions. Facebook, Twitter, and Google Search, along with other technological tools, fall under the umbrella of MALU because they are mostly used by people for non-linguistic outcomes. In contrast, Duolingo or Babel are examples of MALL/CALL (depending on the technology learners use to access the application/website), and they are designed specifically for language learning. Jarvis (2014) points out that in reality, most students are not using technological devices to practice language explicitly; rather, they are 'a means to an end', and the end here is anything other than language learning (p. 28). Thus, he states for the need to shift from MALL/CALL towards MALU to allow for unconscious learning to happen. Therefore, he highlights that CALL and MALL are no longer valid acronyms. MALU encompasses all the attributes of CALL and MALL and recognizes that technological devices can be utilized as the means to an end, the end being language learning and accessing and posting data using English as globally connected citizens (Achilleos \& Jarvis, 2013). However, for the sake of this paper, a new acronym will be introduced as dedicated language learning apps which will be defined as: standalone apps with pre-packed pedagogical approach built into it and it can be used without the presence of an educator.

\subsection{Dedicated Language Learning Apps}

It is important to elaborate more on DLLAs to distinguish between DLLAs and generic apps. Reinders and Pegrum (2016) categorize mobile apps into two categories. One is dedicated apps and the other are generic apps. They state that dedicated apps are those that can be used as a standalone apps which the user can use without the guidance of the teacher; the most popular ones of this kind are Duolingo and Busuu. On the other hand, generic apps, which are apps that are not designed for language learning but can be used for language learning, need to be put in context and their pedagogical use carefully considered by the educator (Reinders \& Pegrum, 2016). For example, Twitter (a microblog app that is not designed for language learning) can be used as a language learning activity (see appendix 2) This paper is primarily concerned with apps that are designed for language learning, hereafter referred to as Dedicated Language Learning Apps (DLLAs) standalone apps with pre-packed pedagogical approach built into it and it can be used without the presence of an educator. The figure below gives an overview on the difference between language learning mobile apps by Rosell-Aguilar (2017). 


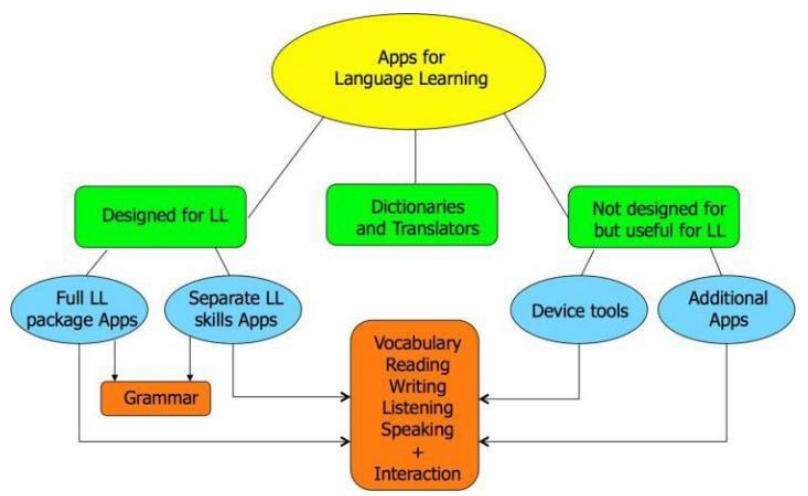

Figure 1. Apps for language learning taxonomy

\subsection{Second Language Acquisition Theories}

Since this paper is considered with DLLAs in addition to SLA. It is thus important to give an overview on the main SLA theories. That is to say, the individual theories - to the utmost extent possible - are reviewed not only to pave way for pedagogical improvement, but also to guide the design of instructional aids that operate toward that particular regard.

\subsubsection{Behaviorism}

Behaviorism is one of the first significant SLA theories. In this theory, second language learning is viewed as the development of a new set of habits (Gass \& Selinker, 2008). According to this theory, learners associate between words and objects or events when they receive linguistic input (Lightbown and Spada, 2013). For example, a dog can associate the ring of a bell to food. Because of this view that language is viewed as a habit, behaviorism highly depends on repetition, imitation and substation drills (Lightbown \& Spada, 2013). In other words, it breaks tasks down to small steps; it takes the idea that the learner is an empty page which needs to be filled with linguistics knowledge by drills and practices which focus on forms and accuracy.

\subsubsection{Cognitivism}

The cognitive theory offers a more complex explanation on how a second language in acquired, a stance which came as a direct reaction against the behavioristic approach. Cognitivism emphasizes that the mental process we use for our general cognitive function to learn anything in life is the same as with language (Hummel, 2014). It also suggests that learners are using their brains to find or notice patterns; they deduce information and analyze language in order to acquire language. In other words, their minds are involved in the learning process which forces them to take chances, make mistakes and figure things out linguistics patterns for themselves. Thus, we can see that cognitivism stress that it is not simply behavior leads to language acquisition rather it involves brain processing.

\subsubsection{Inputism}

The input hypothesis was driven by the work of Krashen (1985, in Ellis, 2015). Krashen states that L2 acquisition is completely input-driven which means output does not necessarily enhance L2 acquisition. Krashen states that if the input is comprehensible, (that is, the input is comprehensible if the input is one level beyond the learner's current level or, i+1) (Hummel, 2014: 73). Therefore, he argues that the learner will acquire the second language if he is espoused to enough comprehensible input (Hummel, 2014). According to Tomlinson (2010b), in order to ensure that learners are exposed to a rich and comprehensible input of language, materials should allow learners to experience language in use which is meaningful to the targeted learners. In other words, second languages are learned by understanding massages (Gass \& Selinker, 2008).

\subsubsection{Interactionism}

According to Ellis (2015) the interaction hypotheses highlights that language acquisition is best acquired through modifying learners' output while the negotiating meaning. This is to say that the teacher corrects the learners' output when there is a communication problem (Richards \& Rodgers, 2014). The interaction hypothesis highlights that, through interaction, learners have the chance to notice things related to language use (e.g. how to apologies), and this awareness turns input into intake (VanPatten \& Benati, 2010). Interactionism proposes that when the interaction is modified, this makes the input more compensational (Hummel, 2014). The input is only modified to negotiate meaning; in other words, learners are interrupted to help them understand what is the conversation is about (Gass \& Selinker, 2008). This hypothesis, however, is different from inputism in the sense that simply exposing the learner to comprehensible input is not enough - the role the learner plays in the interaction with the input is also important. 


\subsubsection{Socio-Constructivism}

This theory is a joint perspective of constructivism and sociocultural theories which highlights that an individual's learning takes place because of his or her interactions in a group and that learners are involved in their own learning process (Hummel, 2014; Richards \& Rodgers, 2014). According to this school of thought, both learner and environmental factors are of critical concern. Yet, it is the specific interaction between these two camps that serves to establish knowledge - in our case, linguistic knowledge. Socio-constructivists therefore insist that learning occur in realistic settings (e.g. using language for communicative purposes) and that the learning tasks that underlie the design and construction of the teaching tools that they use be particularly relevant to students' actual experiences (Bada, 2015). This theory derives from Vygotsky (1962) who argues that language learning is first constructed through social interaction. Vygotsky also introduced what he calls the "zone of proximal development" (ZPD) which he defines as the gap between what the learner can accomplish alone and what can be done by cooperating with others who are more skillful (cited in Warschauer, 1997; 471). Vygotsky argues that collaborative learning with other individuals through their ZPD is important for learning a language. In other words, learning happens when the learners are faced with something a little beyond what they know in which they try to solve it together by scaffolding each other; it also can happen between a teacher and a learner or a group or learners - this is also known as collaborative learning (Richards \& Rodgers, 2014).

\subsection{Relevant Research}

Kim \& Kown (2012) reviewed 87 language learning apps not only in terms of the technology but also reviewed the apps from an SLA perspective. They reviewed the apps according to three categories:

- Content Target: identify intended users

- Procedure and Approach: analyzing the apps from pedagogical and SLA perspective

- Technological Features: looking at the technological function that the apps provide and the ease of use

Kim \& Kown concluded that language learning apps provide a learner-centered approach and flexible usage. However, they do not provide collaborative learning opportunities as most apps' primary focus is on language form. The study did not give a clear definition on what is a language learning app. Thus, making it difficult for the reader to understand what they consider a language learning app. Vesselinov and Greog (2012) researched the effectiveness of the Duolingo app, which is a dedicated language learning app. Their report found that significant language improvement from the 88 learners who took a placement test before and after using Duolingo for a period of time. However, the results are questionable for two main reasons. The first concern addressed by Krashen (2014) who points out that 78.8\% of participants either agreed or strongly agreed that they were 'satisfied with Duolingo'. However, does 'satisfied' mean anything when it comes to measuring the success of language acquisition of an app? Krashen (2014) also states that the report first had 156 learners starting the program and nowhere in the report mentions the reasons for 68 learners to leave the program. The second concern is that the placement test which tested the learners' improvements in their language skills was not attached to the paper; I would then assume that the test could have focused on linguistics competence which does not test the learners' ability to communicate. As Ellis (1992) state that learners tend to use their own linguistic resources over the ones they have practiced when they are preforming meaningful and communicative tasks. Therefore, I believe that the report they have presented is not reliable.

\subsection{Research Questions}

- What are the common and distinctive features of DLLAs?

- What stage of MALL/CALL do DLLAs reflect? And why?

- What theories of second language acquisition underpin DLLAs?

To answer the research questions an analysis framework will be applied on a range of dedicated language learning apps.

\section{Methodology and Analysis}

\subsection{App Collection}

The procedure to select the apps was done by searching 'Learn English' in the Apple Store. Many apps appeared from the search, however, only dedicated language learning apps that we have defined earlier in the literature review were appropriate: apps that are self- contained and do not require the presence of a teacher for the learner to use. Thus, other language learning apps such as translators and dictionaries were not taken into consideration. As they do not fit the definition we provided because it has no pedagogical approach for language learning. The procedure resulted in the collection of 20 DLLAs. These apps will be analysed by following an analytic framework designed for DLLAs which 
will be explained and presented in the next section. Each of these 20 apps were downloaded and explored in depth by examining each app for an average of 2 hours on each app and exploring all the functions including the ones that had to be purchased to use. The analysis followed an analytical framework that I have adapted from the work of Littlejohn (2011), which was originally designed to analyse English language learning materials. However, I have added the SLA and CALL theories to make it more appropriate to understand DLLAs. Which will allow the researcher to get a clear understanding of how each app functions and what does it provides.

\subsection{The Analytic Framework for DLLAs}

Table 1. Analytic Framework for DLLAs

\begin{tabular}{l}
\hline Actions \\
$\begin{array}{l}\text { Wanguage Focus } \\
\text { Scaffolding Tools } \\
\text { Collaborative Learning }\end{array}$ \\
$\begin{array}{l}\text { Are there any scaffolding tools? What are the tools? } \\
\text { Focus On }\end{array}$ \\
$\begin{array}{l}\text { Mental Operation } \\
\text { Input }\end{array}$ \\
Mechanical practice; Meaningful practice; Communicative practice \\
Extended discourse: written \\
Extended discourse aural \\
Words/phrases/sentences: written \\
Words/phrases/sentences: aural \\
Output \\
Words/phrases/sentences: oral \\
Words/phrases/sentences: written \\
Written coherent text with connected sentences \\
Oral coherent text with written sentences
\end{tabular}

MALL Approach

What approach of MALL do DLLAs reflect?

Restricted; Open; Integrated

SLA Approach

What theories of second language learning underpin DLLAs?

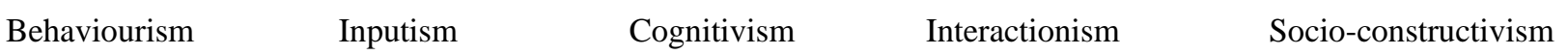
Mechanical Practice
Meaningful Practice
Communicative Practice
Limited Output/Input
Extended Input
Extended Output/Input
No Collaborative Learning
Collaborative Learning
No Scaffolding Tools
Scaffolding Tools

Figure 2. Second language acquisition theories

Figure 2 gives an overview on how each app will be classified according to the SLA theories that have been introduced in this paper. For example, if an app provides mechanical practice, limited output/input, no collaborative learning, and with no scaffolding tools. Then it will be classified as a behaviouristic app which will reflect a restricted type of MALL. However, one app could underpin more than one SLA theory. For example, an app could be underpinned by both behaviourism and inputisim if it gave the user an authentic text followed by grammar and vocabulary drills. 


\section{Analyses and Discussions}

This section will report the findings of the analysis and discuss it. The full analysis and results can be found in Appendix 1.

\subsection{Language Skill Focus}

Table 2. DLLAs Language Skills

\begin{tabular}{lcc}
\hline Focused skills & Number of applications & Mean percentage \\
\hline Vocabulary & 11 & 22.9 \\
Grammar & 10 & 20.8 \\
Listening & 8 & 16.6 \\
Reading & 8 & 16.6 \\
Speaking & 7 & 14.5 \\
Writing & 4 & 8.3
\end{tabular}

As illustrated above, the three figures show that DLLAs are fairly well-balanced across language skills, except writing skills which was significantly the least covered skill accounting for about $8 \%$ apps only, whereas vocabulary was the most covered language skill amongst DLLAs, representing almost $30 \%$ of the total apps. It is important to note that if an app is designed to test users' reading skill, it can also have an explicit focus on vocabulary. In this case it will be classified as focusing on both reading and vocabulary skills. The findings here are very similar to those of Kim and Kwon (2012) in their study. They reported that vocabulary apps were the most common, representing a mean percentage of about $42 \%$ whereas writing represented only $5.7 \%$.

\subsection{Scaffolding Tools in DLLAs}

The analysis found that the vast majority of apps do not offer scaffolding tools for the user to use while completing the task. Narayanan \& Kumar (2018) stress that mobile language learning apps are not oriented towards communicative competence because scaffolding is not easy to provide, since this highly depends on the teacher to successfully scaffold the learners for communicative outcomes. I would agree with the previous statement; however, I would argue that scaffolding the learner for linguistic outcomes (when focusing on forms) is not hard to achieve in DLLAs; the analysis showed that 5 out of 20 provided scaffolding tools in the following ways:

- Embedded dictionaries (for the user to look up words meaning)

- Grammar rules (giving an example of a grammar rule)

- Giving a piece of the answer to the user (hint)

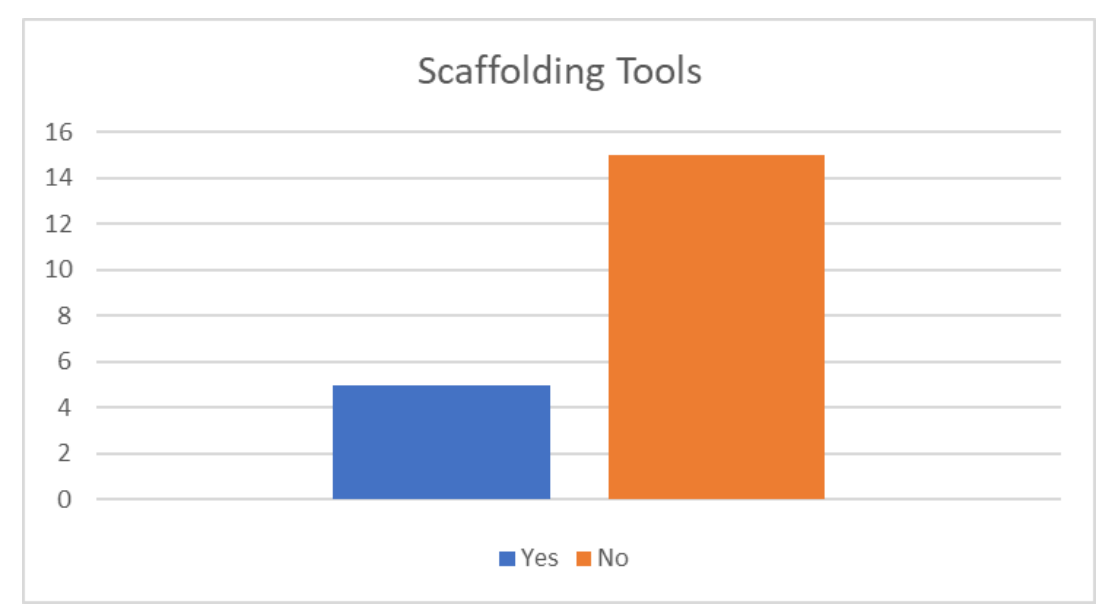

Figure 3. DLLAs scaffolding tools

These types of scaffolding can help the user in completing the task. However, the problem here is that all the apps which provided these scaffolding tools were providing them to help the user complete a form-focused question. For 
example, if a user encountered a word that they do not understand, they can look it up in the embedded dictionary. Thus, they are not using the scaffolding tools to solve a communication breakdown where the focus is on meaning.

\subsection{Collaborative Learning}

Figure 4 indicate that most dedicated language learning apps (DLLAs) do not facilitate collaborative learning, as most apps provide interaction with the technology only. That is to say that the user is not interacting with real people, rather they are interacting with the app itself. Collaborative interaction in second language acquisition has been marked as an important element, especially in the socio-constructivist approach (Hummel, 2014). By collaborative learning we mean that two or more learners join together to solve a problem, negotiate meaning, discuss opinions, or simply communicate in L2 (Kukulska-Hulme \& Viberg, 2018). Vygotsky (1962) argues that collaborative learning is important for assisting learners in advancing through their zone of proximal development (ZPD), which is the gap of what the learner can achieve alone and what the learner can achieve in collaboration with more skillful people (Warschauer, 1997). I strongly stress that DLLAs should be focusing on collaborative learning as it helps the learners to find their ZPD where they can learn from more experienced people. In fact, Donato (1994) found that learners can scaffold each other in ways similar to how experienced people such as teachers can scaffold their learners (Schmid, 2017). Collaborative learning can create opportunities for learners to practice their language skills and probably construct new knowledge (Kukulska-Hulme \& Viberg, 2018).

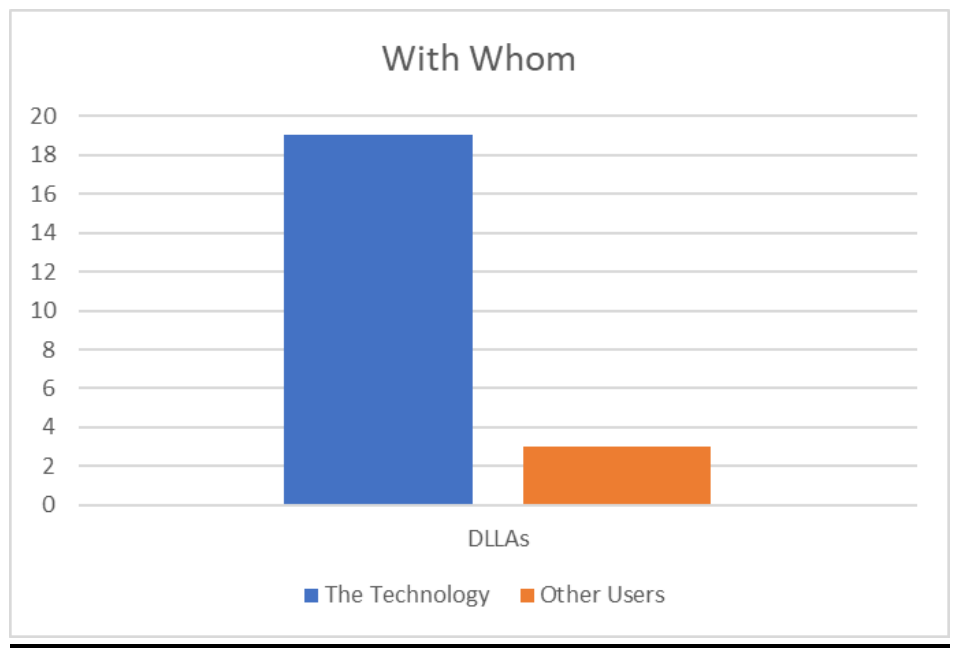

Figure 4. DLLAs interaction

I believe that the key in collaborative interaction is that the learner uses whatever language resources they have in order to communicate with other individuals, which then allows the learner to construct their own language skills without the teacher forcing them to use certain forms of language. Surprisingly, the DLLAs analysed did not facilitate this kind of learning, although technology makes it easy for people to communicate through the internet. It seems that the DLLAs did not take advantage of that and preferred to let the user interact solely with the technology. This has raised a concern from educators that DLLAs are disregarding the collaborative learning environment that web 2.0 is providing (Reinders \& Pegrum, 2016).

\subsection{DLLAs Focus and Operation}

The vast majority of DLLAs showed that the focus is mainly on language systems (82\%) whereas focus on meaning was barely found (18\%). However, within the focus on language system it is important to first distinguish between the focus on form and the focus on forms. The first occurs in a communicative task where the focus on form arises from the teacher and/or learners if there is a communicative breakdown (Ellis, 2005). The latter 'focus on forms', according to Long (1991) refers to teaching pre-selected linguistic items where the primary focus in on forms not meaning (cited in Ellis, 2005). Unfortunately, the apps that focus on language system are in fact focusing on forms. One of the main drawbacks of focus on forms is that it provides linguistic forms in isolation rather than in context which means it presents a simplified input which represents a behaviourism view that linguistics knowledge is the only knowledge learners need to take into a habit to learn a language (Naeb, 2015), thus resulting in an unrealistic use of language rather than authentic language use (Widdowson, 1972, cited in Naeb, 2015). 


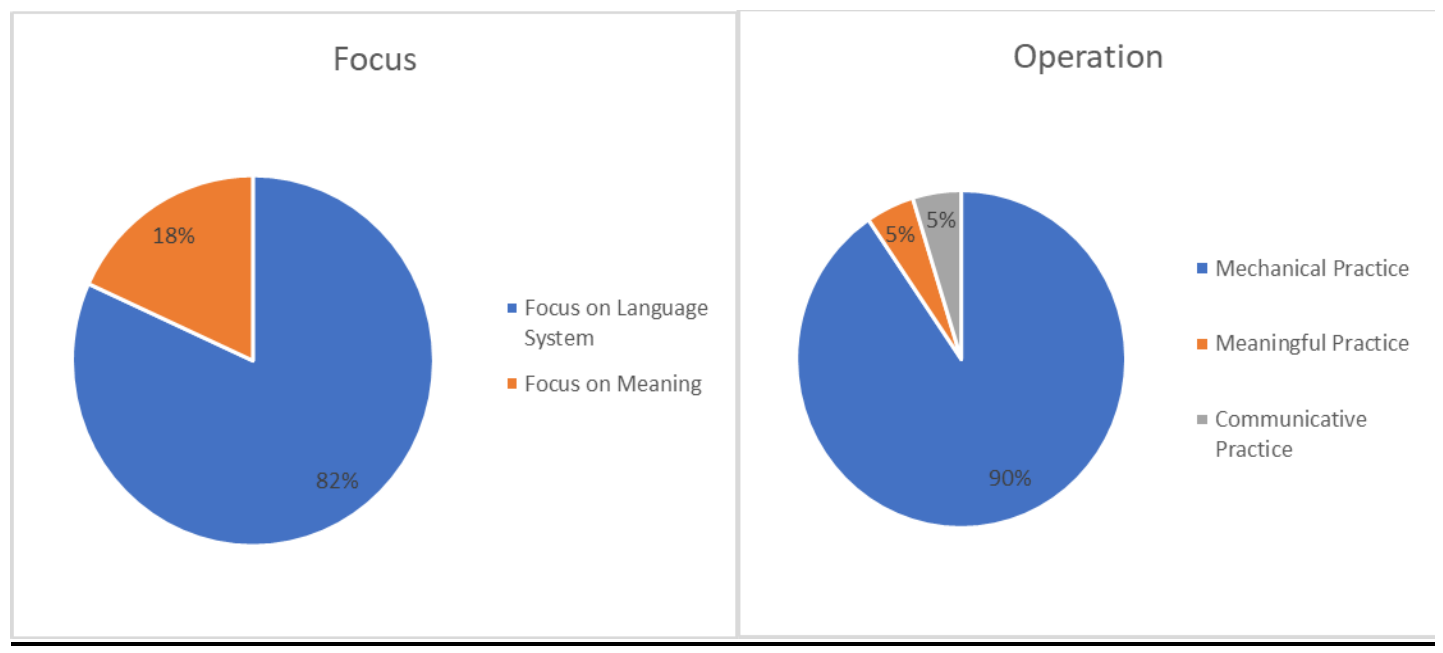

Figure 5. DLLAs focus \& operation

The focus on forms comes from the fact that the vast majority of the practices that DLLAs provide were mechanical practices such as translating a sentence, multiple choice, true or false or gap filling, also known as drill-and-kill practices, whereas meaningful practices, which refers to an activity where language focus is present but provides the user with meaningful choices (the user is given a map with different location and asking questions such as where is the bookstore?). Communicative practices which refer to when an activity offers real information exchange with other people and where the language is not predictable for the user. Both meaningful and communicative practises represented only 5\% each of the activities offered, respectively. Here there is a lack in developing communicative competence. Before discussing communicative competence, it is important to contrast it with linguistic competence to give us a clear understanding. Linguistic competences refer to the knowledge of spelling, pronunciation, vocabulary, word formation, grammatical structure, sentence structure, and linguistic semantics (Hedge, 2000). It was traditionally believed that if a learner masters such competence then they will be able to use them appropriately. However, Richards (2006) highlights that, although linguistic competence plays an important role in language learning, learners still need to obtain communicative competence in order to use the language for meaningful communication.

It is clear from the analysis that the vast majority of dedicated language learning apps (DLLAs) are not providing users with the opportunities to interact in meaningful conversation, nor do they aim to improve the users' communicative competence. This is mainly because most DLLAs do not provide the users a chance to interact with other users. In addition, the main focus is on forms, which only develops their linguistic competence. Moreover, most of the practices provided for the users are mechanical practices, which again only develop users' linguistic competence. Thus, to develop users' communicative competence, users must be provided with communicative practice which, according to Richards (2006), requires the learner to use language within a real-life communication context, where real information is exchanged (for instance, negotiating meaning, expressing opinions, and so on).

\subsection{Content Input \& Output}

Figures $7 \& 8$ are important as they look at the content which the user is learning from. Earlier in this section the data showed the language areas that DLLAs focus on, as well as showing that writing skills are the least focused on (see Table 2). However, writing is not only the least emphasized skill; only 2 apps provided the user the opportunity to write extended coherent text with connected sentences, while the other 2 apps only provided opportunities for limited written output. This also seems to be the case for speaking skills, since out of the 7 apps which cover speaking skills, only one app provided the user with the opportunity to produce coherent oral text. Input was slightly better in terms of extended discourse: 10 apps provided extended discourse, 6 of which were aural and 4 written, whereas most apps provided limited discourse for the user to be exposed to. 


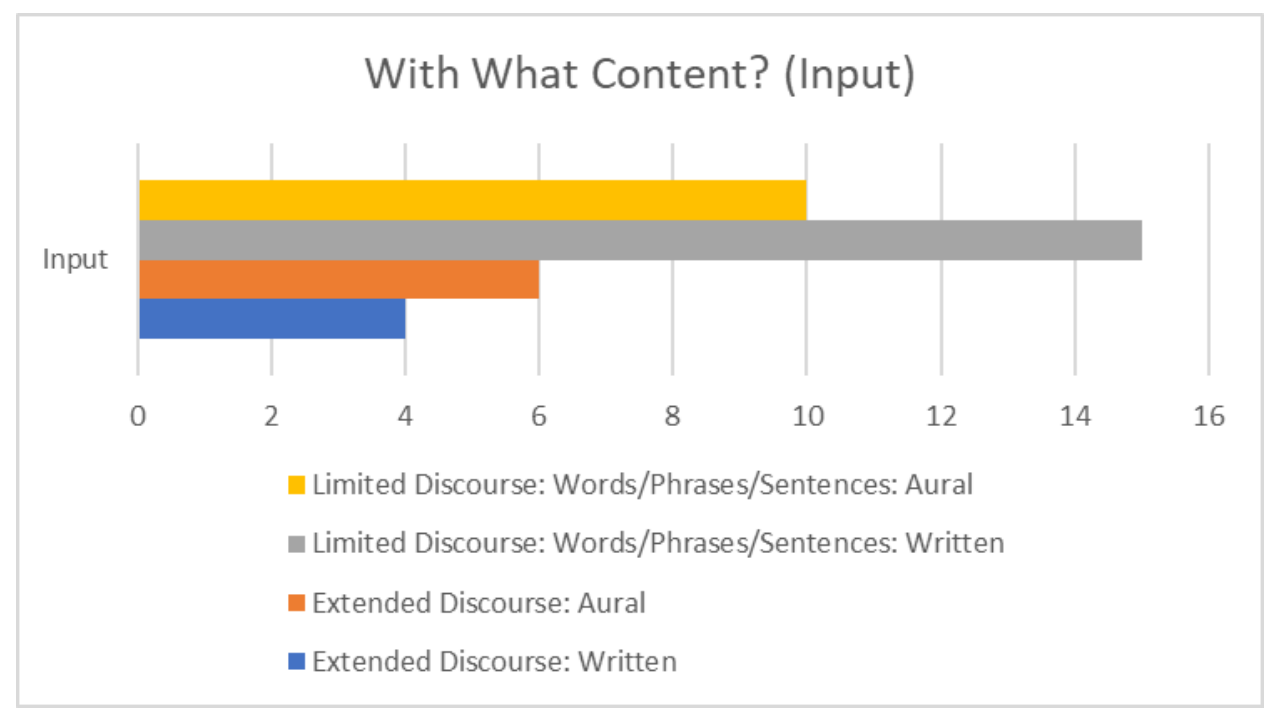

Figure 6. DLLAs input content

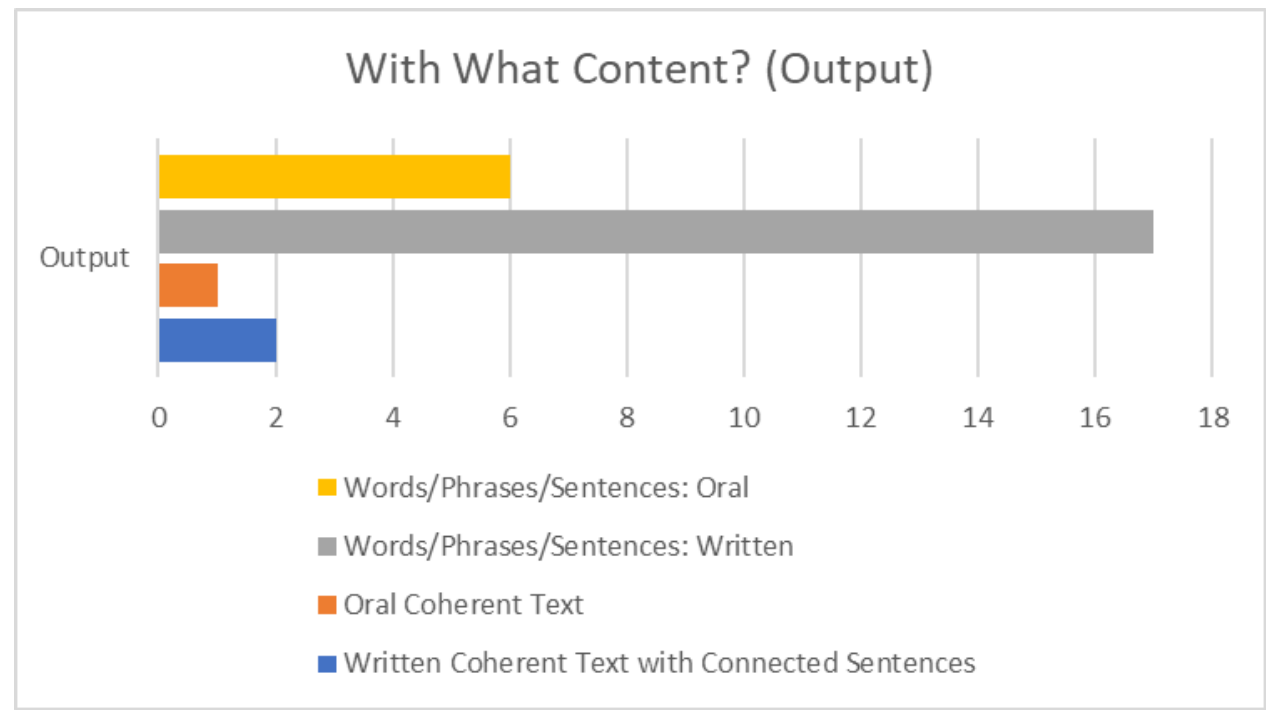

Figure 7. DLLAs output content

These numbers backup the argument made in the precious section that DLLAs lack focus on improving communicative competence, as to develop this competence there are two essential elements which need to be available (Tomlinson \& Masuhara, 2018; Tomlinson, 2013a; Tomlinson, 2010a). The first is opportunities for purposeful communication in the second language which DLLAs lack because only few apps promote the user to output orally or in written extended coherent discourse. The second important element is exposure to real language in use, which DLLAs also lack since most apps provide the users with limited input for them to notice how language is used in real life.

\subsection{DLLAs CALL Approach}

Restricted CALL/MALL features closed tasks, also known as drill-and-kill, which consists of repetitions, translation, multiple-choice, and gap filling. Bax (2003); Warschauer and Healy (1998) stated that the restricted, or structural CALL/MALL stage ended by the late 1980s. However, our results of the analysis show that $90 \%$ of DLLAs represent restricted MALL, thus this stage still exists now in 2019. Walker and White (2011) also argued that Bax and Warschauer's claims are not true, and that restricted MALL/CALL still exists. 


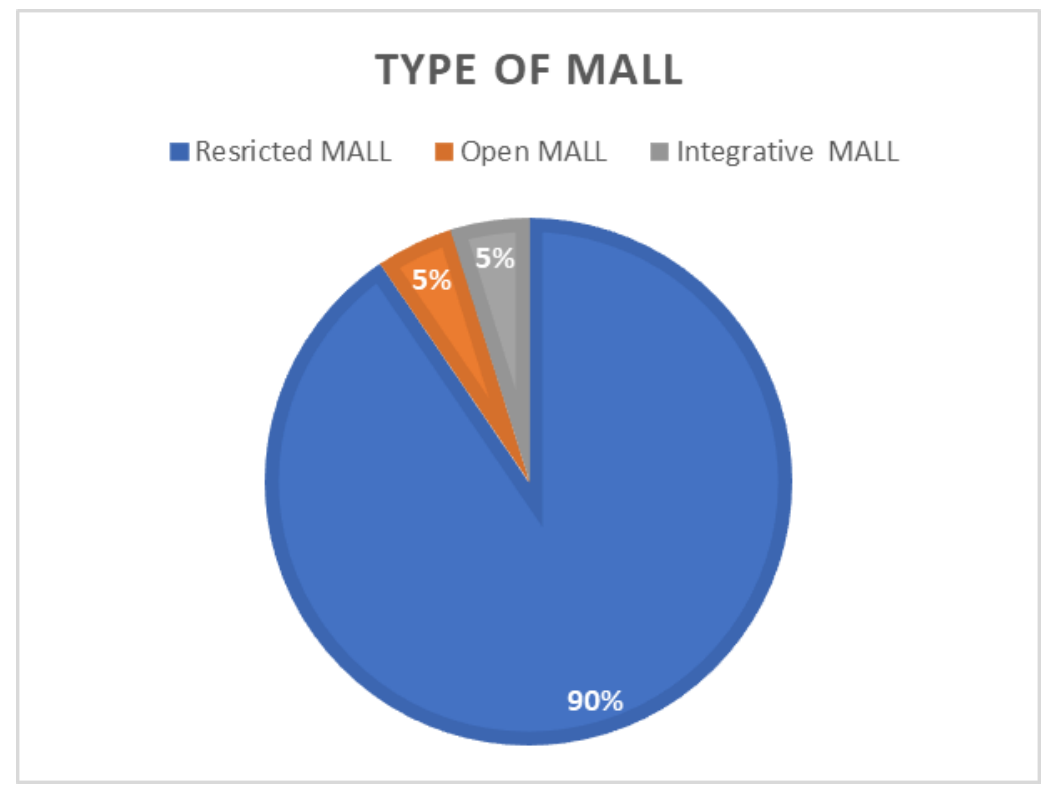

Figure 8. DLLAs type of MALL

The unanswered question here is: why does restricted MALL still exist? Technology is a fast-changing industry on the rise; it seems odd that we are still replicating the first stages of the integration of technology with education. What DLLAs are representing is nowhere near the potential of technology aiding language learning. I believe that most apps are still in the restricted MALL stage because apps are seen as a behaviourist tutor (Levy, 1997). This belief comes from Skinner's (1954) views where he argues that the teacher is no longer needed if there are DLLAs that provide drills and practices (Levy, 1997). However, this is not true as simply developing linguistic competence does not mean that the learner has learned the language. As Ellis (1992) states that learners tend to use their own linguistics recourses over the ones they practiced in meaningful and communicative tasks. For DLLAs to move for open and integrative MALL they need to focus more on engaging user cognitively with the task and also focus on improving users' communicative competence. Thus, I would argue that at the meantime since DLLAs are not developed to target various language competences, mainly communicative competence, there is currently a need to move from viewing apps as a tutor to viewing them as a tool to take the optimal advantage from technology. When the technology is acting as a tool then it only can be used within the presence of the teacher to pedagogically drive the tool for language learning purposes. The teacher, however, can either use the technology in a flipped classroom which is more similar to DLLAs as they can be done outside the classroom or in a blended classroom.

\subsection{DLLAs SLA Approach}

According to behaviourist theory, learning is recognized when either the form or frequency of observable performance changes. An example is when the student replies " 6 " when presented with an flashcard reading " $2+4=$ ?" Behaviourism insists that positive responses that are followed up by positive reinforcement are more likely to present favourably in the future. No attempt is made to determine how the student is structuring their knowledge or what processes they rely upon to evoke it. Focusing upon environmental factors, behaviourists strive to assess learners' behaviours to determine when and where to begin instruction and what flavours of reinforcement are most appropriate to which individual learner. The behaviourist insists that transfer, that is, the application of learned knowledge to new situations, occurs as a result of generalization. Situations that exploit identical or similar features enable the student to broaden their understanding of classifying similarities and differences, making various tasks increasingly easy over time (Ertmer \& Newby, 2013). 


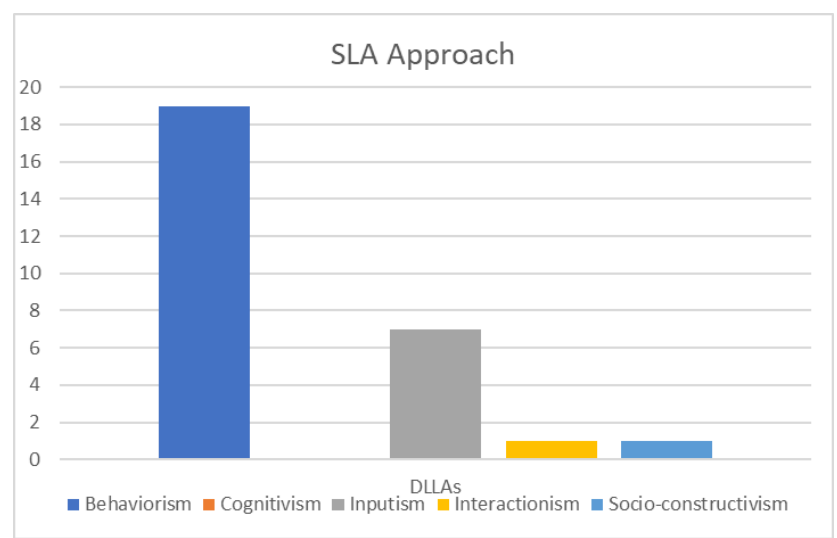

Figure 9. DLLAs SLA approach

Unfortunately, language learning apps fall down in all of these areas. They generally focus upon drill rather than reinforce the understanding of concepts and associations, by focusing on repetitive scenarios (behaviourism) rather than upon ones that build atop lessons already mastered (cognitivism). The second language acquisition field of study is way beyond the behaviouristic view that Skinner introduced in the 1950s. One could at least expect that the cognitive view of language learning where the learner is introduced with meaningful practices. However, not one DLLA represented a cognitive view. The socio-constructivist approach was reflected in only one app; as mentioned earlier, the internet has made the world a smaller place, therefore people can easily communicate with one another wherever they are. Thus, taking language learning beyond the classroom walls is not a difficult case nowadays, especially when looking at language learning from a socio-constructivist view where simply communicating with other people can help a person build new language skills. Rosell-Aguilar (2018) claims that apps can provide meaningful, collaborative, and interactive environments for the user. However, the analysis has shown that this claim is not true at all. Burston (2014) rightly argues that dedicated language learning apps (DLLAs) have not yet reached their potential and that it is a matter for pedagogy, not technology, to fully realize DLLAs. Bruston also stresses that DLLAs are replicating each other with no innovation. The same issue occurs with coursebooks; Tomlinson (2013a) points out that publishers are cloning other coursebooks which sell well. Kim \& Kwon (2012) on the other hand also stress that DLLAs lack the opportunity to engage in collaborative learning. However, it seems that behaviouristic DLLAs (e.g. Duolingo) are still popular tools that learners still prefer using over language exchange DLLAs (e.g. Tandem) (Rosell-Aguilar, 2017).

Rosell-Aguilar (2017) conducted a survey on over 4,000 learners and found that over $45 \%$ of participants preferred using behaviouristic DLLAs while only 3\% preferred language exchange DLLAs and only 2\% used non-dedicated language learning apps (e.g. YouTube) for language learning. I would argue that just simply because learners prefer using a certain type of app does not make it a useful tool for language learning. Perhaps these learners feel positive towards using these apps because they are achieving high scores in tests that focus on forms, while if they are to engage in a communicative task they might fall backwards and lack communicative competence. This links to Ellis' (1992) point that learners tend to use their own linguistic recourses over the ones they practiced in meaningful and communicative tasks. Thus, I believe that if an app is underpinned by the socio-constructivism theory can improve the users' communicative competence as we will see in the next section.

This paper believes that DLLAs can provide more than what is currently provided; rather than using the technology as a behaviouristic tutor, they can provide collaborative learning by using the technology as a tool for communication between learners, also knownas computer-mediated communication (CMC). Burston (2014: 344) argues that the future of DLLAs lies in the exploitation of communication and the multimedia affordances of mobile devices in a way which supports collaborative, task-based learning both within and outside of the classroom. However, one app from the analysis was exploited in the manner that Burston describes, which will be discussed in the following section.

\subsection{Communicative DLLA}

As illustrated in fig. 9, interactionism and socio-constructivism each had been represented by one app; in fact, it is only one app that represented them both in addition to the input hypothesis. Socio-constructivism argues that collaborative learning with other individuals through their zone of proximal development is important for learning a language. The Tandem app, is an app that provides a communication platform for people who are willing to learn a language through equal language exchange previously described in this paper. Through this people communicate with another more skilful person (a native speaker of the language they wish to learn) which suggests that they are developing their 
language skills through their zone of proximal development (ZPD). The communication can take place by texting, video calls, or phone calls. This app sets up the integrative stage of MALL where the technology is seen as a tool for communication. This app also enables learners to employ more language skills and learn in the process via reading, writing, speaking and listening (Warschauer \& Healy, 1998). Moreover, it exposes users to meaningful language in use (comprehensible input) allowing them to notice how language is used in real life (e.g. integrate skills) and to notice grammatical patterns which can then be acquired implicitly.

\subsection{The Common and Distinctive Features of DLLAs}

The findings concluded that the vast majority of DLLAs have the following features in common:
- $\quad$ No collaborative learning
- $\quad$ Provide mechanical practices where the focus is on form
- $\quad$ Output and input are limited
- Underpinned by a behaviouristic view of language learning
- $\quad$ Represent restricted MALL
- $\quad$ No scaffolding tools for the user while completing tasks
- $\quad$ Lack the focus on improving communicative competence

\section{The Future of DLLAs}

Perhaps the argument that Tomlinson (2013a) presented about global coursebooks where he assessed and found a weak match between the coursebooks and the current SLA principles also applies to DLLAs. The SLA principles that Tomlinson mentions (2013a) include cognitive engagement; being allowed to focus on meaning; and purposeful communication in the second language. DLLAs are not different from coursebooks as both are pre-packed materials with the content and the pedagogy underpinning the materials. The main diffrenece is that DLLAs are designed to be used without the presence of the teacher whereas coursebooks are. Thus, it is more appropriate to compare DLLAs with self-access materials which function the same way as DLLAs, where the learner can access and learn language without the presence of a teacher.

Similar to the findings on DLLAs, according to Tomlinson \& Masuhara, 2018), self- access materials also seem to favor drills and practice that focuses on language systems, which lacks exposure to authentic language in use and lacks opportunities for purposeful communication in the second language. Tomlinson \& Masuhara stress that this is partly because self-access materials cannot offer interaction with other people. They suggest that forming a club or a community of speakers from a specific language can solve this problem by offering learners a chance to develop their communicative competence. To back their suggestion, they refer to Barker (2010), where a community of language speakers was formed in a university in Japan where students met in a community where communication was restricted to English only. Thus, the members of the community had many opportunities for purposeful communication (cited in Tomlinson \& Masuhara, 2018). I found it odd that DLLAs do not facilitate such a thing; perhaps one of the most fundamental options that DLLAs can provide is purposeful communication in the second language and exposure to authentic language in use. In fact, Jarvis (2014) argues that the goal in MALL or as he wish to call it MALU, should focus on enabling learners to become globally connected citizens in English as a second language, which will give plenty opportunities for learners to be exposed to language in use and thus they can pick up language incidentally.

\section{Conclusion, Implications, and Further Research}

Apps are becoming increasingly popular as tools to facilitate learning. However, at the same time, they suffer from many weaknesses. Many educators feel that apps are broadly unconstructive as learning tools (Hirsh-Pasek et. al, 2015). Kerr (2014: 8) stress that dedicated language learning apps invest more time and money in their technology than educational expertise (Hockly, 2015). Moreover, Burston (2014) states that mobile-assisted language learning (MALL) has not yet reached its potential and that it is a matter for pedagogy not technology to fully realize MALL. A survey of such apps reveals a thoroughly haphazard approach to the presentation of material that seems more concerned with quickly establishing a marketplace presence atop the mobile platform than with quality of pedagogy. Thus, this paper analysis supports both Burston (2014) and Kerr (2014) state that pedagogy investment is missing in dedicated language learning apps (DLLAs). There are several reasons for this. The first is that designers of ostensibly educational apps typically know little, if anything, about underlying theories of pedagogy. Rather, many apps tend to be focused on keeping the viewer's attention focused so that time can be expended and that, in certain cases, in-app purchases can be advertised. Second, apps offer a relatively limited opportunity for fruitful engagement. From the perspective of 
socio-constructivism, language learning apps fail miserably. They do not demonstrate the capability to build upon the learner's past experiences. Rather, they focus on repetition of the same recurrent patterns. It is actually a surprise that this is the case, given the physical restrictions of the platform only a handful of mechanisms for interaction with the material.

This paper, however, suggests that due to the severe pedagogical drawback in the current DLLAs, for the meantime, educators should invest more time in trying to implement non-DLLAs, also introduced here as generic apps which are not designed specifically for language learning. These can offer more for language learning as well-educated people with pedagogical awareness can build activities around them that can promote the main SLA principles that Tomlinson (2013a) outlined. Dudeney et. al, (2013) have already moved towards this step and provided more than 40 activities with generic apps for implication in a blended classroom environment. However, since about the focus here is self-access materials, there is a need in the future to investigate how can these generic apps can serve as self-access materials where the teacher guides learners on how to use these apps for language learning or perhaps in a flipped classroom where learners use these apps before coming to class. We suggest that to get the best out of DLLAs, there is a need to focus on reflecting more than just the behaviourist theory in DLLAs to try achieving a link between SLA principles and language learning apps which can move DLLAs into the integrative stage of CALL/MALL rather than the restricted CALL/MALL that DLLAs currently represent.

\section{References}

Bax, S. (2003). CALL - Past, present, and future. System, 31, 13-28. https://doi.org/10.1016/S0346-251X(02)00071-4

Bax, S. (2011). Normalization revisited: The effective use of technology in language education. In computer-assisted language learning and teaching Edited by The Editor-in- chief. International Journal of Computer-Assisted Language Learning and Teaching, 1(2). https://doi.org/10.4018/ijcallt.2011040101

Burston, J. (2014). MALL: The pedagogical challenges. Computer Assisted Language Learning, 27(4), 344-357. https://doi.org/10.1080/09588221.2014.914539

Davis G. el. al (2014). Historical perspectives on CALL. In Thomas, M., Reinders, H., \& Warschauer, M. (2014). Contemporary computer-assisted language learning. London: Bloomsbury.

Dudeney, G., Hockly, N., \& Pegrum, M. (2013). Digital literacies. Milton Park: Taylor \& Francis.

Ellis, R. (1992). On the relationship between formal practice and second language acquisition. Neueren Sprachen, 91(2). https://doi.org/10.4324/9781315832913

Ellis, R. (2005). Instructed second language acquisition. Wellington, NZ: Research Division, Ministry of Education.

Ellis, R. (2015). Understanding second language acquisition 2nd edition-Oxford applied linguistics. Oxford university press.

Ertmer, P. A., \& Newby, T. J. (2013). Behaviorism, cognitivism, constructivism. Performance Improvement Quarterly, 26(2), 43-71. https://doi.org/10.1002/piq.21143

Gass, S. M., \& Selinker, L. (2008). Second language acquisition: An introductory course (3rd ed.). New York, NY: Routledge. https://doi.org/10.4324/9780203932841

Hedge, T. (2000). Teaching and learning in the language classroom. Oxford: Oxford University Press.

Hirsh-Pasek, K., Zosh, J. M., Golinkoff, R. M., \& Gray, J. H. (2015). Putting education in 'educational' apps: Lessons from the science of learning. Psychological Science in the Public Interest, 16(1), 3-34. https://doi.org/10.1177/1529100615569721

Hockly, N. (2015). Developments in online language learning. Elt Journal, 69(3), 308-313. https://doi.org/10.1093/elt/ccv020

Hockly, N. (2016). Focus on learning technologies. Oxford: Oxford University Press.

Hummel, K. (2014). Introducing second language acquisition. Hoboken: John Wiley \& Sons.

Hung, H. (2014). Flipping the classroom for English language learners to foster active learning. Computer Assisted Language Learning, 28(1), 81-96. https://doi.org/10.1080/09588221.2014.967701

Jarvis, H. (2012). Computer and learner autonomy: trends and issues. ELT Research Papers 12-02. London: British Council. 
Jarvis, H. (2014). Digital residents: Practices and perceptions of non-native speakers. In P. Robertson and J. Adamson (Eds.), The Asian EFL Journal professional teaching articles (pp.). Asian EFL Journal Press.

Jarvis, H., \& Achilleos, M. (2013). From computer assisted language learning (CALL) to mobile assisted language use (MALU). The Electronic Journal for English as a Second Language, 16(4), 1-18.

Kerr, P. (2014). Adaptive Learning. The Round. Available at http://the-round.com/resource/a-short-guide-to-adaptive-learning-in-english-language-teaching/

Kim, Heyoung \& Kwon, Yeonhee. (2012). Exploring smartphone applications for effective mobile-assisted language learning. Multimedia-Assisted Language Learning, 15(1), 31-57. https://doi.org/10.15702/mall.2012.15.1.31

Krashen, S. (2014). Does Duolingo "trump" university-level language learning. International Journal of Foreign Language Teaching, 9(1), 13-15.

Kukulska-Hulme, A., \& Shield, L. (2008). Overview of mobile assisted language learning: From content delivery to supported collaboration and interaction. ReCALL, 20(3), 271289. Language Classrooms. Language Teaching, v46 n1, 1-40. https://doi.org/10.1017/S0958344008000335

Kukulska-Hulme, A., \& Viberg, O. (2018). Mobile collaborative language learning: State of the art. British Journal of Educational Technology, 49(2), 207-218. https://doi.org/10.1111/bjet.12580

Levy, M. (1997). Computer-Assisted Language Learning: Context and Conceptualization. In Hubbard, P. (2009). Foundations of CALL. London: Routledge.

Lightbown, P. M., \& Spada, N. (2013). How languages are learned 4th edition-Oxford Handbooks for Language Teachers. Oxford university press.

Littlejohn, A. (2011). 'The analysis of language teaching materials: inside the Trojan Horse. In Tomlinson, B. (Ed.) Materials Development in Language Teaching. Cambridge: Cambridge University Press. Pages 179-211

Narayanan, A., \& Kumar, R. (2018). Computer-Aided Scaffolding in Communicative Language Teaching Environments. CALL-EJ, 20(1), 19-32. http://callej.org/journal/20-1/Narayanan-Kumar2019.pdf

Reinders, H., \& Pegrum, M. (2016). Supporting language learning on the move. SLA research and materials development for language learning, 219.

Richards, J. C. (2006). Communicative language teaching today. Language Teaching, 25. https://doi.org/10.2307/3587463

Richards, J. C., \& Rodgers, T. S. (2014). Approaches and methods in language teaching. Cambridge university press.

Rosell-Aguilar, F. (2017). State of the app - A Taxonomy and Framework for Evaluating Language Learning Mobile Applications. CALICO Journal, 34(2), 243-258.

Rosell-Aguilar, F. (2018) Autonomous language learning through a mobile application: A user evaluation of the busuu app. Computer Assisted Language Learning, 31(8), 854-881. https://doi.org/10.1080/09588221.2018.1456465

Schmid, E. C. (2017). Teacher education in computer-assisted language learning: A sociocultural and linguistic perspective. Bloomsbury Publishing.

Tomlinson, B. (2010a). Principles and procedures for self-access materials. Studies in Self- Access Learning Journal, 1(2), 72-86. https://doi.org/10.37237/010202

Tomlinson, B. (2010b). Principles of effective materials development. In N. Harwood (Ed.), English Language Teaching Materials - Theory and Practice (pp. 81-108). New York: Cambridge University Press.

Tomlinson, B. (2013a). Second language acquisition and materials development. In B. Tomlinson (Ed.), Applied Linguistics and Materials Development (pp. 11-29).London: Bloomsbury.

Tomlinson, B. (2013b). Developing materials for language teaching ( $2^{\text {nd }}$ ed.). London: Bloomsbury.

Tomlinson, B., \& Masuhara, H. (2018). Developing materials for the acquisition of language. In The Complete Guide to the Theory and Practice of Materials Development for Language Learning. Hoboken, NJ: WILEY Blackwell.

VanPatten, B., \& Benati, A. (2010). Key terms in second language acquisiton. London: Bloomsbury.

Vesselinov, R., \& Grego. J. (2012). Duolingo effectiveness study [PDF file]. http://static.duolingo.com/s3/DuolingoReport_Final.pdf 
Vygotsky, L. S. (1967). Play and its role in the mental development of the child. Soviet psychology, 5(3), 6-18. https://doi.org/10.2753/RPO1061-040505036

Walker, A., \& White, G. (2013). Technology enhanced language learning. Oxford: Oxford University Press.

Warschauer, M. (1997). Computer-mediated collaborative learning: Theory and practice. The Modern Language Journal, 81(4), 470-481. https://doi.org/10.1111/j.1540-4781.1997.tb05514.x

Warschauer, M., \& Healey, D. (1998). Computers and language learning: an overview. Language Teaching, 31(2), 57-71. https://doi.org/10.1017/S0261444800012970 
Appendix 1

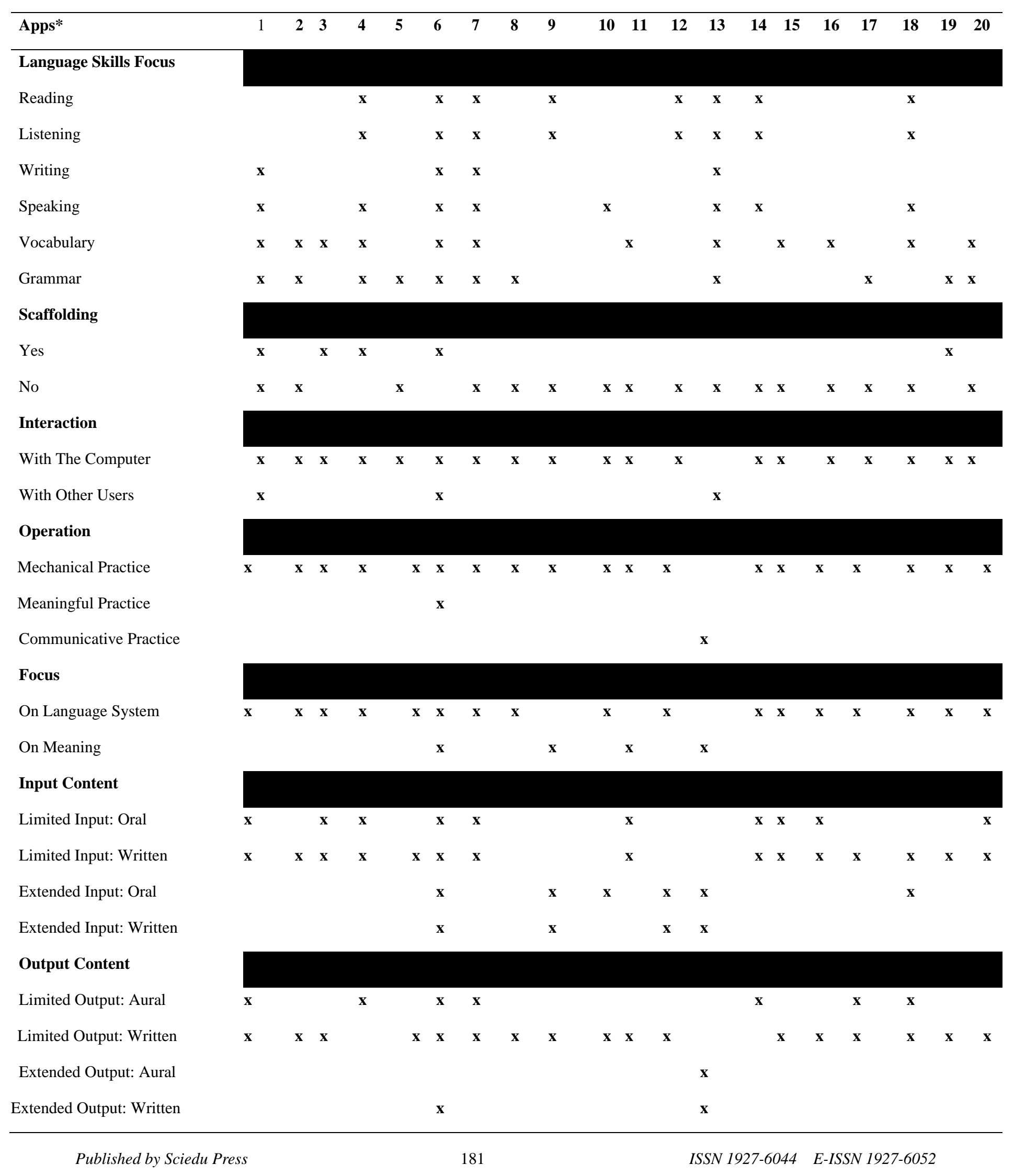




\begin{tabular}{|c|c|c|c|c|c|c|c|c|c|c|c|c|c|c|c|c|c|c|c|c|}
\hline \multicolumn{21}{|l|}{ Type of MALL } \\
\hline Restricted & $\mathbf{x}$ & $\mathbf{x}$ & $\mathbf{x}$ & $\mathbf{x}$ & $\mathbf{x}$ & $\mathbf{x}$ & $\mathbf{x}$ & $\mathbf{x}$ & $\mathbf{x}$ & $\mathbf{x}$ & $\mathbf{x}$ & $\mathbf{x}$ & & $\mathbf{x}$ & $\mathbf{x}$ & $\mathbf{x}$ & $\mathbf{x}$ & $\mathbf{x}$ & $\mathbf{x}$ & $\mathbf{x}$ \\
\hline Open & & & & & & $\mathbf{x}$ & & & & & & & & & & & & & & \\
\hline Integrative & & & & & & & & & & & & & $\mathbf{x}$ & & & & & & & \\
\hline \multicolumn{21}{|l|}{ SLA Approach } \\
\hline Behaviourism & $\mathbf{x}$ & $\mathbf{x}$ & $\mathbf{x}$ & $\mathbf{x}$ & $\mathbf{x}$ & $\mathbf{x}$ & $\mathbf{x}$ & $\mathbf{x}$ & $\mathbf{x}$ & $\mathbf{x}$ & $\mathbf{x}$ & $\mathbf{x}$ & & $\mathbf{x}$ & $\mathbf{x}$ & $\mathbf{x}$ & $\mathbf{x}$ & $\mathbf{x}$ & $\mathbf{x}$ & $\mathbf{x}$ \\
\hline \multicolumn{21}{|l|}{ Cognitivism } \\
\hline Inputism & & & & & & $\mathbf{x}$ & & & $\mathbf{x}$ & $\mathbf{x}$ & & $\mathbf{x}$ & & $\mathbf{x}$ & & & & $\mathbf{x}$ & & \\
\hline Interactionism & & & & & & & & & & & & & $\mathbf{x}$ & & & & & & & \\
\hline Socio-constructivism & & & & & & & & & & & & & $\mathbf{x}$ & & & & & & & \\
\hline
\end{tabular}

\section{Apps*:}

1. Duolingo

2. Johnny G

3. Lingo Play

4. Rosetta Stone

5. British Council Grammar

6. Busuu

7. Mondly

8. Sentence Master

9. British Council: Learn English

10. FluentU

11. Memrise

12. British Council: Audio \& Video

13. Tandem

14. Falou

15. Bright

16. Atlas English

17. Hello English

18. ABA English

19. Modals

20. Xeropan

\section{Copyrights}

Copyright for this article is retained by the author(s), with first publication rights granted to the journal.

This is an open-access article distributed under the terms and conditions of the Creative Commons Attribution license (http://creativecommons.org/licenses/by/4.0/). 